\title{
Leukotoxicity of Aggregatibacter actinomycetemcomitans in generalized aggressive periodontitis in Brazilians and their family members
}

\author{
Virginia Régia Souza SILVEIRA ${ }^{1}$, Márcia Viana Bessa NOGUEIRA ${ }^{1}$, Nádia Accioly Pinto NOGUEIRA², Vilma LIMA ${ }^{3}$, \\ Flávia Aparecida Chaves FURLANETO ${ }^{4}$, Rodrigo Otávio REGO 5
}

\footnotetext{
1- Graduate Program in Dentistry, Faculty of Pharmacy, Dentistry and Nursing, Federal University of Ceará, Fortaleza, CE, Brazil.

2- Department of Clinical and Toxicological Analyses, Faculty of Pharmacy, Dentistry and Nursing, Federal University of Ceará, Fortaleza, CE, Brazil.

3- Department of Physiology and Pharmacology, Faculty of Medicine, Federal University of Ceará, Fortaleza, CE, Brazil.

4- Division of Periodontics, Department of Surgery and Integrated Clinic, Dental School of Araçatuba, Univ. Estadual Paulista - UNESP, Araçatuba, SP, Brazil.

5- Department of Dentistry, School of Dentistry at Sobral, Federal University of Ceará, Sobral, CE, Brazil.
}

Corresponding address: Rodrigo Otávio Rêgo - Curso de Odontologia de Sobral - Universidade Federal do Ceará - Rua Stanislau Frota, s/n - $62.011-000$ - Sobral - CE - Brazil - Phone: +55 8599095775 - Fax: +55 8533668232 - e-mail: rodrigorego@yahoo.com

Submitted: March 23, 2013 - Modified: July 13, 2013 - Accepted: July 29, 2013

\section{ABSTRACT}

$\mathrm{O}$ bjective: The purpose of this study was to examine the leukotoxin promoter types of Aggregatibacter actinomycetemcomitans clones in subjects with generalized aggressive periodontitis (GAgP) and in their family members (FM). Material and Methods: Thirty-five

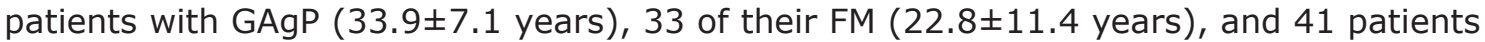
with chronic periodontitis $(C P)(44.1 \pm 9.4$ years) were clinically analyzed using the plaque index, gingival index, probing depth (PD), and clinical attachment level (CAL). Subgingival biofilm samples were collected from four interproximal periodontal sites ( $>$ PD and $>C A L$ ) of each patient. The presence of $A$. actinomycetemcomitans and its leukotoxic clone was confirmed by polymerase chain reaction (PCR). Results: $A$. actinomycetemcomitans was observed in $23(51.1 \%)$ GAgP patients and $16(30.1 \%)$ CP patients. Thirty-seven $(94.8 \%)$ patients showed minimally leukotoxic strains and $2(5.1 \%)$ showed highly leukotoxic strains. In the FM group, $10(30.3 \%)$ had aggressive periodontitis (AgP), $12(36.3 \%)$ had $\mathrm{CP}, 11(33.3 \%)$ were periodontally healthy or had gingivitis, and $12.2 \%$ were $A$. actinomycetemcomitans positive. Greater full mouth PD and CAL were observed in GAgP patients positive for the bacteria than those negative for it $(p<0.05)$, and the presence of A. actinomycetemcomitans positively correlated with GAgP (Odds ratio, 3.1 ; confidence interval, 1.4-7.0; $\mathrm{p}=0.009$ ). Conclusions: The presence of $A$. actinomycetemcomitans was associated with the clinical condition of GAgP, with most patients exhibiting a generalized form of the disease and minimally leukotoxic clones. Most of the relatives of GAgP patients presented either CP or AgP.

Keywords: Aggregatibacter actinomycetemcomitans. Leukotoxin. Periodontitis.

\section{INTRODUCTION}

Aggregatibacter actinomycetemcomitans is a gram-negative, capnophilic coccobacillus ${ }^{13}$, that is strongly associated with aggressive periodontitis $(\mathrm{AgP})^{14}$. Despite being considered a periodontopathogen, $A$. actinomycetemcomitans can frequently be detected in periodontally healthy individuals, suggesting variability in its virulence ${ }^{20}$. The microorganism produces several virulence factors that may be involved in the destruction of periodontal tissues, the most important among them being the leukotoxic activity ${ }^{8,13}$.

Development of techniques to detect the genetic variability of microorganisms has allowed for the observation of genetic differences in the leukotoxin promoter region between various $A$. actinomycetemcomitans strains, which are directly correlated with their leukotoxicity ${ }^{34}$. Strains that are highly leukotoxic have a deletion of 530 base pairs in the leukotoxin promoter region, while those that are 
minimally leukotoxic contain the complete leukotoxin promoter region. Thus, the highly leukotoxic strains (strain JP2) can produce 10 to 20 -fold more toxin than the others, providing them with the potential to interfere with the host's innate immune defense ${ }^{4}$. Some studies have shown that individuals harboring highly leukotoxic strains have a higher risk of $\mathrm{AgP}^{5,15,16}$, resulting in further progression of clinical attachment level $(C A L)^{17,18}$. However, most of these studies assessed patients with localized $\operatorname{AgP}^{5,15,28,29,35}$, while only a few evaluated generalized $\operatorname{AgP}(\mathrm{GAgP})^{8,15,16}$.

Some studies have examined the transmission of $A$. actinomycetemcomitans between family members ${ }^{11,17,26,28}$. Besides genetic predisposition, transmission of $A$. actinomycetemcomitans can be considered a favorable hypothesis to explain the familial aggregation of individuals with $\mathrm{AgP}^{15,18}$. Patients who carried the JP2 clone were from families in which at least one other individual exhibited the disease ${ }^{5}$.

$\mathrm{AgP}$ is more prevalent in subjects of African ancestry, and it is hypothesized that besides host susceptibility, specific $A$. actinomycetemcomitans clones with enhanced leukotoxic activity are associated with the disease in these populations ${ }^{8}$. These particular clones could have been disseminated worldwide over centuries and might be related to the onset of $\mathrm{AgP}$ in different ethnic groups ${ }^{10,15}$. A study has shown that, in Brazil, skin color is not directly related to genomic ancestry ${ }^{23}$; the immense heterogeneity of the Brazilian population may make it difficult to predict race-related diseases or microorganisms. Indeed, the present study evaluated individuals from one of the three vast metropolitan areas of northeastern Brazil. Distinct from other populations that are predominantly African-American, this population is miscegenous, a blend over the years of white European, AfricanAmerican, and some indigenous populations, with no clear predominance of any race ${ }^{3}$.

Therefore, the evaluation of the periodontal and microbiological status of individuals with AgP in this population is relevant. The purpose of this study was to examine the leukotoxin promoter types of A. actinomycetemcomitans clones in subjects with GAgP and in their family members.

\section{MATERIAL AND METHODS}

\section{Selection of subjects}

This study was conducted in 35 patients with GAgP (test group) and one to four of their immediate family members (FM). A total of 33 relatives of $26 \mathrm{GAgP}$ patients were included. A group of 41 patients with chronic periodontitis $(C P)$ were used as the control group. Subjects were selected among patients who sought care at the Periodontology
Clinic, Faculty of Pharmacy, Dentistry and Nursing, at the Federal University of Ceará, Brazil.

$\mathrm{AgP}$ patients were classified according to the clinical criteria suggested by the American Academy of Periodontology (AAP) ${ }^{30}$ as follows:

Localized AgP: interproximal attachment loss on at least two permanent teeth, involving no more than two teeth other than the incisors and the first molars;

GAgP: generalized interproximal attachment loss affecting three permanent teeth other than the first molars and incisors. The disease affects systemically healthy individuals and results in rapid attachment loss and bone destruction;

$\mathrm{CP}$ patients were also classified according to the criteria of the AAP $14,21,22$ as follows:

Slight to moderate destruction: characterized by the presence of periodontal sites with a probing depth (PD) of up to $6 \mathrm{~mm}$ and CAL of up to $4 \mathrm{~mm}$;

Advanced destruction: characterized by the presence of a PD greater than $6 \mathrm{~mm}$ and CAL greater than $4 \mathrm{~mm}$.

Exclusion criteria were as follows: periodontal treatment within the previous 6 months, antibiotic therapy within the previous 3 months, and systemic alterations that could have interfered with the periodontal conditions. The relatives of GAgP patients should have at least the first permanent molars.

The research protocol was approved by the Ethics Committee, Federal University of Ceará, Brazil. All participants or guardians were informed about the purpose of the study and provided written consent.

\section{Clinical measurements}

Clinical measurements were made on all the completely erupted permanent teeth, except the third molars, using a periodontal probe (PCP-UNC 15, Trinity, São Paulo, SP, Brazil). The following parameters were evaluated: plaque index ${ }^{1}$, gingival index ${ }^{1}, \mathrm{PD}$, and CAL. PD and CAL were taken at six sites per tooth (mesiobuccal, buccal, distobuccal, mesiolingual, lingual, and distolingual). A single examiner evaluated all the clinical periodontal parameters, and the measurement reproducibility was calculated by using the intraclass correlation coefficient (ICC) for PD and CAL. The agreement between replicate measurements was high $($ ICC $>0.80)$.

\section{Microbiological sampling}

The supragingival plaque was removed with curettes and sterile cotton pellets, and the area was isolated with sterile cotton rolls. Subgingival plaque samples were collected by means of two sterile paper points (size 35) at each site, for 20 seconds (Dentsply Maillefer 35, Dentsply, Rio de Janeiro, RJ, Brazil) and stored separately. They were collected from four proximal tooth sites with greater CAL and increased PD. In FM without 
periodontal disease, the subgingival plaque samples were collected from four proximal sites of the first permanent molars or incisors. All the samples were immersed in microtubes containing $1 \mathrm{~mL}$ of Ringer's sterile solution ${ }^{9}$ and stored at $-80^{\circ} \mathrm{C}$ until they were processed.

\section{Microbiological evaluation}

The microtubes containing the samples were thawed on ice. The bacterial cells or suspension were dispersed by vortexing at maximal setting for $1 \mathrm{~min}$ and centrifuged at $12,000 \times \mathrm{g}$ for $10 \mathrm{~min}$. Genomic DNA was extracted from the pellet (InstaGene Matrix, Bio-Rad Laboratories, Hercules, CA, USA) and $20 \mu \mathrm{L}$ aliquot of the resultant supernatant was added to $30 \mu \mathrm{L}$ of the reaction mixture containing $25 \mu \mathrm{M}$ polymerase chain reaction (PCR) buffer (Promega Corporation, Madison, WI, USA), $25 \mu \mathrm{M}$ $\mathrm{MgCl}_{2}$ (Promega Corporation, Madison, WI, USA), 0.2 $\mu \mathrm{M}$ dNTP mix (Promega Corporation, Madison, WI, USA), $1.25 \cup$ Taq polymerase (Promega Corporation, Madison, WI, USA), and $100 \mathrm{ng}$ of each primer (Invitrogen, São Paulo, SP, Brazil), resulting in a final volume of $50 \mu \mathrm{L}$. Negative and positive controls were included in each reaction.

First, $P C R$ with specific primers ( $5^{\prime}$ - G G A C TAYA G G TATCTAAT- $3^{\prime}$; 5'-AGAGTTTGATCMTGG-3') for the $16 \mathrm{~S}$ ribosomal DNA (16S rDNA) was performed to confirm the presence of bacterial DNA ${ }^{33}$. Subsequently, the samples were evaluated by PCR with specific primers for the presence of $A$. actinomycetemcomitans ( 5 ' - A A A C C CATCTCTGAGTTCTTCTTC- 3 ' ; 5'-ATGCCAACTTGACGTTAAAT-3')2. Once confirmed, the samples were analyzed for the presence of the leukotoxin operon using the primers Itx 3 (5'-GCCGACACCAAAGACAAAGTCT-3') and Itx4 (5'-GCCCATAACCAAGCCACATAC-3') as previously described ${ }^{24}$. The primers resulted in amplicons of 686 and 1.216 bp from strains of the JP2 clone and non-JP2 clone respectively, used as controls.

Amplification (Biocycler, Biosystems, Curitiba, PR, Brazil) of the $16 \mathrm{~S}$ rDNA and $A$. actinomycetemcomitans DNA was performed at an initial cycle at $94^{\circ} \mathrm{C}$ for 10 min, followed by 30 cycles at $96^{\circ} \mathrm{C}$ for $30 \mathrm{~s}, 55^{\circ} \mathrm{C}$ for $30 \mathrm{~s}$ and $72^{\circ} \mathrm{C}$ for $30 \mathrm{~s}$, with the final extension at $72^{\circ} \mathrm{C}$ for $10 \mathrm{~min}^{15}$. For the leukotoxin promoter region, amplification was performed at an initial cycle at $94^{\circ} \mathrm{C}$ for $5 \mathrm{~min}$, followed by 30 cycles at $94^{\circ} \mathrm{C}$ for $1 \mathrm{~min}, 60^{\circ} \mathrm{C}$ for $1 \mathrm{~min}$ and $72^{\circ} \mathrm{C}$ for $2 \mathrm{~min}$, followed by a final extension at $72^{\circ} \mathrm{C}$ for $8 \mathrm{~min}^{24}$.

The amplification products were analyzed by electrophoresis on an agarose gel and stained with ethidium bromide $(10 \mu \mathrm{g} / \mathrm{mL})$. A $1.5 \%$ gel was used to assess the $16 \mathrm{~S}$ rDNA and the presence of $A$. actinomycetemcomitans, while a $2.0 \% \mathrm{gel}$ was used to assess the $A$. actinomycetemcomitans clonal diversity. The gels were stained with ethidium bromide and photographed (Canon Powershot A640, Canon, USA) under ultraviolet light (LTA/LTB GE, Loccus Biotecnologia, São Paulo, SP, Brazil).

PCR was repeated three times for each sample. JP2 (A. actinomycetemcomitans JP2) and non-JP2 ( $A$. actinomycetemcomitans HK1605) reference strains were used to determine the detection levels of the PCR method. The strains were serially diluted 10-fold, followed by PCR as with the samples. The detection limits for $A$. actinomycetemcomitans and leukotoxin promoter region primers were approximately $10^{2}$ and $10^{3}$ colony-forming units (CFU) of the microorganism, respectively. These detection levels were similar to that described previously ${ }^{2,24}$.

\section{Statistical analysis}

The clinical data set was tested for normality using the Kolmogorov-Smirnov test. Comparisons between three groups (GAgP, CP, and RM) were made by ANOVA or Kruskal-Wallis. Comparisons between two groups (GAgP and CP) were made by the unpaired $t$-test or Mann-Whitney $U$ test. Odds ratio (OR) analysis was used to assess the relationship between the presence of $A$. actinomycetemcomitans and the occurrence of AgP. A difference of $p<0.05$ was considered statistically significant. All data analysis was performed using the GraphPad Instat software (Graph Pad Software Inc, San-Diego, CA, USA).

\section{RESULTS}

The sample comprised 109 individuals divided into three groups divided into GAgP, FM, and $\mathrm{CP}$. Among the FM group, 10 had AgP, 12 had $C P$, and 11 were periodontally healthy or had gingivitis (Figure

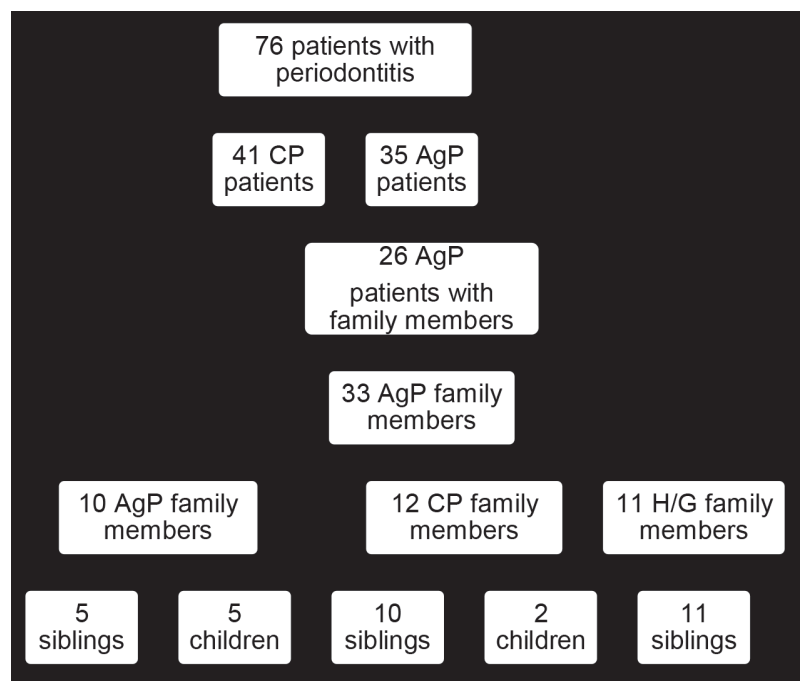

$\mathrm{AgP}=$ aggressive periodontitis; $\mathrm{CP}=$ chronic periodontitis; $H / G=$ periodontally healthy or gingivitis

Figure 1- Flowchart of the study population 
1). Among all the subjects with $\mathrm{AgP}(\mathrm{n}=45)$, only one subject in the FM group presented localized AgP - a 10-year-old boy, while others presented with GAgP.

Clinical data of the subjects are summarized in Table 1. A statistically significant difference between the ages of all groups was observed. The GAgP patients presented signs of more severe periodontal destruction and inflammation, as observed from the significantly higher mean PD than the CP and FM groups. CAL was also higher in the GAgP group followed by the CP group (Table 1 ).

In Table 2, all subjects, including the FM, were grouped based on their periodontal condition and the presence of $A$. actinomycetemcomitans.
Twenty-three (51.2\%) GAgP and 16 (30.2\%) CP patients presented the bacteria. The presence of A. actinomycetemcomitans was associated with the clinical condition of $\mathrm{AgP}(\mathrm{OR}, 3.1$; confidence interval, 1.4-7.0, $p=0.009$ ). Among the FM group, 3 patients with $\mathrm{AgP}$ and 1 with $\mathrm{CP}$ were positive for the bacteria. In healthy/gingivitis patients, the microorganism was not detected. Full mouth PD and CAL in GAgP patients positive for $A$. actinomycetemcomitans were higher than those in patients negative for it $(p<0.05)$.

Among all the patients who were positive for A. actinomycetemcomitans, $37(94.8 \%)$ exhibited minimally leukotoxic strains and $2(5.1 \%)$, a man and a woman aged 37 and 31 years old, respectively,

Table 1- Clinical periodontal parameters (mean \pm standard deviation) of subjects with generalized aggressive periodontitis $(\mathrm{GAgP})$, chronic periodontitis (CP), and their family members (FM)

\begin{tabular}{cccc}
\hline Parameters & GAgP & FM & CP \\
\hline N & 35 & 33 & 41 \\
\hline Age (years) & $33.9 \pm 7.1$ & $22.8 \pm 11.4$ & $44.1 \pm 9.4^{*}$ \\
Number of teeth & $25.0 \pm 2.3$ & $24.2 \pm 5.3$ & $22.0 \pm 3.5$ \\
\hline PD fm (mm) & $3.7 \pm 0.9^{*}$ & $2.4 \pm 0.5$ & $2.9 \pm 0.5$ \\
\hline CAL fm (mm) & $4.3 \pm 1.2^{* * *}$ & $2.0 \pm 1.4$ & $3.8 \pm 1.1$ \\
\hline Gl fm (\%) & $14.9 \pm 10.5$ & $10.7 \pm 13.5$ & $20.6 \pm 19.0^{* *}$ \\
PI fm (\%) & $32.3 \pm 19.7$ & $24.8 \pm 19.6$ & $33.5 \pm 14.0^{* *}$ \\
PD ss (mm) & $9.8 \pm 2.1^{*}$ & $5.3 \pm 2.0$ & $8.2 \pm 2.3$ \\
\hline CAL ss (mm) & $10.7 \pm 2.8^{* * *}$ & $4.6 \pm 3.3$ & $9.4 \pm 2.9$ \\
\hline
\end{tabular}

*Statistically significant difference between the groups

**Statistically significant difference between the CP and FM groups

${ }^{* * *}$ Statistically significant difference between the groups, except GAgP and CP

PD: probing depth; CAL: clinical attachment level; GI: gingival index; PI: plaque index; fm: full mouth; ss: sampled sites for microbial analysis

Table 2- Clinical periodontal parameters (mean \pm standard deviation) and the presence of $A$. actinomycetemcomitans in all subjects with aggressive periodontitis (AgP), chronic periodontitis (CP) or periodontally healthy/gingivitis $(H / G)$

\begin{tabular}{ccccccc}
\hline Parameters & \multicolumn{2}{c}{ AgP } & \multicolumn{2}{c}{ CP } & \multicolumn{2}{c}{ H/G } \\
\hline & Aa+ & Aa- & Aa+ & Aa- & Aa+ & Aa- \\
N & $23^{*}$ & 22 & 16 & 37 & - & 11 \\
$\%$ & $51.2 \%$ & $48.8 \%$ & $30.2 \%$ & $69.8 \%$ & - & $100 \%$ \\
Age (years) & $33.5 \pm 7.5$ & $28.7 \pm 10.0$ & $43.1 \pm 9.9$ & $41.1 \pm 10.6$ & - & $12.7 \pm 3.3$ \\
PD fm (mm) & $3.8 \pm 0.9^{* *}$ & $3.2 \pm 0.7$ & $2.9 \pm 0.5$ & $2.7 \pm 0.5$ & - & $1.9 \pm 0.2$ \\
CAL fm (mm) & $4.4 \pm 1.3^{* *}$ & $3.6 \pm 0.9$ & $3.7 \pm 1.1$ & $3.5 \pm 1.2$ & - & - \\
\hline PD ss (mm) & $9.7 \pm 2.6$ & $8.5 \pm 2.0$ & $8.1 \pm 2.0$ & $7.5 \pm 2.4$ & - & $3.3 \pm 0.9$ \\
CAL ss (mm) & $10.5 \pm 3.5$ & $9.1 \pm 2.5$ & $9.4 \pm 2.8$ & $8.4 \pm 3.0$ & - & - \\
\hline
\end{tabular}

*Statistically significant association (odds ratio, 3.1; confidence interval, 1.4-7.0; $p=0.009$ ). Groups that exhibited highly leukotoxin strains

** Statistically significant difference between AgP

PD: probing depth; CAL: clinical attachment level; fm: full mouth; ss: sampled sites for microbial analysis; Aa+: presence of $A$. actinomycetemcomitans; Aa-: absence of $A$. actinomycetemcomitans 
exhibited highly leukotoxic strains with GAgP. The woman was screened subsequent to her brother being diagnosed with GAgP.

\section{DISCUSSION}

This study aimed to evaluate the presence of A. actinomycetemcomitans along with high or low leukotoxicity clones in GAgP patients and their close relatives. The results indicate an association between the presence of $A$. actinomycetemcomitans and the occurrence of GAgP, since $51.1 \%$ of patients with this disease (mean age: 33.5 years) were positive for the microorganism. Several studies have described the occurrence of $A$. actinomycetemcomitans in periodontal disease conditions similar to GAgP. This microorganism was found in $55 \%$ of patients (age range: $14-52$ years) ${ }^{27}$, and in $20 \%$ of adults (range 25-35 years) ${ }^{19}$.

However, only two patients with GAgP presented the highly leukotoxic $A$. actinomycetemcomitans clone, while 21 patients $(91.3 \%)$ with the disease harboring the microorganism exhibited minimally leukotoxic clones. In accordance with previous studies $^{8,12,15,16,20,29}$ they also presented periodontal destruction. Surprisingly, both the patients who harbored the leukotoxic clone were over 30 years of age. Highly leukotoxic clones are strongly associated with localized $\mathrm{AgP}^{5,15,16,35}$. Since this disease is associated with a young age, it could be hypothesized that the JP2 clone has a predilection for younger subjects. Patients harboring the highly leukotoxic strains were much younger (mean age: 12.7 years) than those harboring the minimally toxic $A$. actinomycetemcomitans (mean age: 25.5 years) ${ }^{35}$. It was also observed that subjects with a mean age of 13.9 years were more frequently infected by the JP2 clone, while subjects with a mean age of 35.4 did not show the infection ${ }^{15}$; these results were corroborated by the observations of our present study (mean age: 33.9 years).

Highly leukotoxic strains were not found in patients with periodontitis with mean age of 33.6 years $^{20}$. In another study, 12 out of 94 A. actinomycetemcomitans-positive individuals exhibited the JP2 clone, but only one patient was over 30 years $^{8}$. Among 131 Moroccan schoolchildren positive for $A$. actinomycetemcomitans, $11.5 \%$ presented the JP2 clone ${ }^{16}$. However, their age ranged between 14 and 19 years, much younger than those with AgP evaluated in our current study. Two specific studies revealed the prevalence of the leukotoxic clones in Brazil; both studies associated the young age of the subjects with the prevalence of highly leukotoxic clones of this microorganism ${ }^{10,29}$.

Results from cross-sectional ${ }^{10,15}$ and cohort studies ${ }^{5,35}$ have demonstrated that the JP2 clone can serve as a risk marker for localized AgP in children and adolescents. However, in the current study, the two JP2 clone positive patients were older than what has been described by other authors. Infection with the JP2 clone may have resulted in disease onset at a young age, but it may not necessarily be required for the maintenance of the disease ${ }^{17}$. One explanation for this is that for a majority of the patients evaluated in this study, their clinical periodontal examination was their first ever dental appointment. Lack of treatment resulted in the highly leukotoxic clone being present even at a later age. Another explanation is that the JP2 infection affects the immune tolerance, while other bacteria in the biofilm can sustain and maintain the inflammatory process, which manifests clinically as attachment and bone loss around the teeth. The JP2 clone may be constantly present below the limit of detection, while maintaining the activity of bone resorption ${ }^{17}$. On the other hand, we can hypothesize that the clones can cause periodontal destruction in older subjects as well. However, being a cross-sectional investigation, estimating the onset of the periodontal destruction is difficult.

The microbiological analyses of this study were performed by PCR that only provides information on the presence or absence of the microorganism's DNA, unlike the quantitative data obtained by real-time PCR. However, the detection level of $A$. actinomycetemcomitans and its leukotoxin operon was determined to be around $10^{2}$ and $10^{3} \mathrm{CFU}$, respectively. The vast majority of studies on $A$. actinomycetemcomitans leukotoxin operon have been performed using the PCR technique $4,8,12,14,16,17,29$, which has been found to be highly reproducible and specific for analysis of the JP2 genotype ${ }^{17,24}$.

Another limitation of this study is the lack of a healthy group not related familiarly to the AgP patients. However, it has been shown that in the gingival sulcus of patients without clinical signs of inflammation there is a clear predominance of grampositive bacteria ${ }^{7,25}$. Even when a more sensitive and specific technique was used (i.e. Human Oral Microbe Identification Microarray) and more subgingival sites sampled (14 teeth per patient), $A$. actinomycetemcomitans was not present among the species most commonly found in healthy subjects?.

In the present study, almost all the AgP patients were adults with a generalized disease and exhibited minimally leukotoxic $A$. actinomycetemcomitans clones. These patients, when younger, may have been colonized by highly leukotoxic strains and presented a localized disease, which may have begun with periodontal destruction. This is consistent with the hypothesis that there has been a change in the virulence of $A$. actinomycetemcomitans over time ${ }^{10,15}$. Haubek, et al. ${ }^{18}$ (2007) suggested that highly leukotoxic $A$. actinomycetemcomitans strains comprise a single clone. But, regarding minimally 
leukotoxic strains, Wahasugui, et al. ${ }^{32}$ (2013) found that such strains belonged to 8 different biotypes.

A recent study in Sudanese adolescents (14-19 years) with AgP showed that the $A$. actinomycetemcomitans JP2 clone was not detected in any of the subgingival plaque samples, while nonJP2 clones were detected in $70.6 \%$ of patients with the disease. It can also be suggested that the JP2 clone does not show a general dissemination pattern among various African populations as previously believed $^{12}$. The clone dispersed in America during the slave trade although not from all heritages; it mainly originated from the Mediterranean part of Africa ${ }^{18}$. This can help explain why some patients with the same pattern of disease do not present the JP2 clone. In the present study we evaluated a miscegenous population composed mainly of mixed afrodescendents, Caucasian Europeans and indigenous Brazilians, with no predilection of race. Even during the slave trade, identifying the African region that the subjects originated from was difficult. On arrival, subjects of different origins were sent to different regions of Brazil, which might explain the vast extent of mixed heritage among the Brazilian afrodescendents. A study has shown that in Brazil the race of a person and their genomic ancestry are not correlated $^{23}$. This genetic variability in the Brazilian population may result in differences in susceptibility for colonization by certain microorganisms. This may also explain the low frequency of the highly leukotoxic $A$. actinomycetemcomitans clones found in these subjects.

Another point that can be identified as important in the etiology and spread of the disease is familial transmission of $A$. actinomycetemcomitans ${ }^{11,15,28}$; $64 \%$ of the FM of AgP patients carried the microorganism ${ }^{11}$. On assessing Brazilian families of individuals with localized $\mathrm{AgP}$, it was observed that $41.2 \%$ of parents and $58 \%$ of siblings were also colonized by this bacteria and that $5 \%$ had the JP2 clone $^{28}$. Another study ${ }^{6}$ observed that in FM with localized $\mathrm{AgP}$, the parents were diagnosed with $\mathrm{CP}$ and GAgP. Both parents and children of the subjects were always colonized by minimally leukotoxic $A$. actinomycetemcomitans clones ${ }^{6}$. In a Brazilian indigenous population, all $A$. actinomycetemcomitans strains were non-JP2 clones, even those originated from patients with periodontitis ${ }^{31}$.

The FM group consisted of 18 children and 15 siblings of AgP patients. With regard to their periodontal status, $30.3 \%$ had $\mathrm{AgP}, 36.3 \%$ had $\mathrm{CP}$, and $33.3 \%$ were periodontally healthy or had gingivitis. Among them, $12.2 \%$ were positive for $A$. actinomycetemcomitans, 10 had AgP, and 12 had $\mathrm{CP}$. Only one (3\%) exhibited a highly leukotoxic clone and three ( $9 \%$ ) had minimally leukotoxic clones. Familial aggregation is one important characteristic of the various forms of $\mathrm{AgP}^{6}$. There is a consensus among researchers that genetic factors, with the possible influence of the environment, play a role in this disease 6 . In the present study, most of the close relatives had manifestations of AgP (30.3\%) and $\mathrm{CP}(36.3 \%)$. By evaluating periodontal status and intrafamilial transmission of $\mathrm{AgP}$, it was found that $38 \%$ of FM of AgP had some form of periodontal disease, $19 \%$ had $\mathrm{AgP}$ and $19 \%$ had $\mathrm{CP}^{11}$. According to these investigators, the parents and siblings of a patient with AgP who are positive for $A$. actinomycetemcomitans may exhibit increased susceptibility to destructive periodontal disease ${ }^{11}$.

\section{CONCLUSION}

In conclusion, the presence of $A$. actinomycetemcomitans was associated with GAgP. Most subjects with this disease harboring A. actinomycetemcomitans exhibited minimally leukotoxic clones, while most of the relatives of AgP patients presented either CP or GAgP.

\section{ACKNOWLEDGMENTS}

The authors declare that there are no conflicts of interest in this study. This study was supported by grants CNPq 478161/2007-7, CAPES/PROCAD NF 2313/2008 and CAPES/Pro-Equipamentos 60$01 / 2007$.

\section{REFERENCES}

1- Ainamo J, Bay I. Problems and proposals for recording gingivitis and plaque. Int Dent J. 1975;25:229-35.

2- Ashimoto A, Chen C, Bakker I, Slots J. Polymerase chain reaction detection of 8 putative periodontal pathogens in subgingival plaque of gingivitis and advanced periodontitis lesions. Oral Microbiol Immunol. 1996;1:266-73.

3- Brazilian Institute of Geography and Statistics (IBGE). Síntese de indicadores sociais [online]. Brasília: IBGE; 2010 [cited March 23 ${ }^{\text {rd }}$, 2013]. Available from: http://www.ibge.gov.br/home/ estatistica/populacao/condicaodevida/indicadoresminimos/ sinteseindicsociais2010/SIS_2010.pdf.

4- Brogan JM, Lally ET, Poulsen K, Kilian M, Demuth DR. Regulation of Actinobacillus actinomycetemcomitans leukotoxin expression: analysis of the promoter regions of leukotoxic and minimally leukotoxic strains. Infect Immun. 1994;62:501-8

5- Bueno LC, Mayer MP, DiRienzo JM. Relationship between conversion of localized juvenile periodontitis-susceptible children from health to disease and Actinobacillus actinomycetemcomitans leukotoxin promoter structure. J Periodontol. 1998;69:998-1007. 6- Carvalho FM, Tinoco EM, Govil M, Marazita ML, Vieira AR. Aggressive periodontitis is likely influenced by a few small effect genes. J Clin Periodontol. 2009;36:468-73.

7- Colombo AP, Boches SK, Cotton SL, Goodson JM, Kent R, Haffajee $A D$, et al. Comparisons of subgingival microbial profiles of refractory periodontitis, severe periodontitis, and periodontal health using the human oral microbe identification microarray. J Periodontol. 2009;80:1421-32.

8- Contreras A, Rusitanonta T, Chen C, Wagner WG, Michalowicz BS, Slots J. Frequency of 530-bp deletion in Actinobacillus actinomycetemcomitans leukotoxin promoter region. Oral Microbiol Immunol. 2000;15:338-40. 
9- Cortelli SC, Costa FO, Kawai T, Aquino DR, Franco GCN, Ohara $\mathrm{K}$, et al. Diminished treatment response of periodontally diseased patients infected with the JP2 clone of Aggregatibacter (Actinobacillus) actinomycetemcomitans. J Clin Microbiol. 2009;47:2018-25.

10- Cortelli SC, Jorge AO, Cortelli JR, Jordan SF, Haraszthy VI. Detection of highly and minimally leukotoxic Actinobacillus actinomycetemcomitans strains in patients with periodontal disease. Pesqui Odontol Bras. 2003;17:183-8.

11- Doğan B, Kipalev AS, Okte E, Sultan N, Asikainen SE. Consistent intrafamilial transmission of Actinobacillus actinomycetemcomitans despite clonal diversity. J Periodontol. 2008;79:307-15.

12- Elamin A, Albandar JM, Poulsen K, Ali RW, Bakken V. Prevalence of Aggregatibacter actinomycetemcomitans in Sudanese patients with aggressive periodontitis: a case-control study. J Periodontal Res. 2011;46:285-91.

13- Fine DH, Kaplan JB, Kachlany SC, Schreiner HC. How we got attached to Actinobacillus actinomycetemcomitans: a model for infectious diseases. Periodontol 2000. 2006;42:114-57.

14- Flemmig TF. Periodontitis. Ann Periodontol. 1999;4:32-8.

15- Haraszthy VI, Hariharan G, Tinoco EM, Cortelli JR, Lally ET, Davis E, et al. Evidence for the role of highly leukotoxic Actinobacillus actinomycetemcomitans in the pathogenesis of localized juvenile and other forms of early-onset periodontitis. J Periodontol. 2000;71:912-22.

16- Haubek D, Ennibi OK, Poulsen K, Poulsen S, Benzarti N, Kilian $M$. Early-onset periodontitis in Morocco is associated with the highly leukotoxic clone of Actinobacillus actinomycetemcomitans. J Dent Res. 2001;80:1580-3.

17- Haubek D, Ennibi OK, Vaeth M, Poulsen S, Poulsen K. Stability of the JP2 clone of Aggregatibacter actinomycetemcomitans. ] Dent Res. 2009;88:856-60.

18- Haubek D, Poulsen K, Kilian M. Microevolution and patterns of dissemination of the JP2 clone of Aggregatibacter (Actinobacillus) actinomycetemcomitans. Infect Immun. 2007;75:3080-8.

19- Kamma JJ, Nakou M, Manti FA. Predominant microflora of severe, moderate and minimal periodontal lesions in young adults with rapidly progressive periodontitis. J Periodontal Res. 1995;30:66-72.

20- Mombelli A, Gmur R, Lang NP, Corbert E, Frey J. Actinobacillus actinomycetemcomitans in Chinese adults. Serotype distribution and analysis of the leukotoxin gene promoter locus. J Clin Periodontol. 1999;26:505-10.

21- Parameter on chronic periodontitis with advanced loss of periodontal support. American Academy of Periodontology. J Periodontol. 2000;71:856-8.

22- Parameter on chronic periodontitis with slight to moderate loss of periodontal support. American Academy of Periodontology. J Periodontol. 2000;71:853-5.
23- Pena SD, Bastos-Rodrigues L, Pimenta JR, Bydlowski SP. DNA tests probe the genomic ancestry of Brazilians. Braz J Med Biol Res. 2009;42:870-6.

24- Poulsen K, Ennibi OK, Haubek D. Improved PCR for detection of the highly leukotoxic JP2 clone of Actinobacillus actinomycetemcomitans in subgingival plaque samples. J Clin Microbiol. 2003;41:4829-32.

25- Rego RO, Oliveira CA, Santos-Pinto A, Jordan SF, Zambon JJ, Cirelli JA, et al. Clinical and microbiological studies of children and adolescents receiving orthodontic treatment. Am J Dent. 2010;23:317-23

26- Rêgo RO, Spolidorio DM, Salvador SL, Cirelli JA. Transmission of Aggregatibacter actinomycetemcomitans between Brazilian women with severe chronic periodontitis and their children. Braz Dent J. 2007;18:220-4.

27- Rodenburg JP, van Winkelhoff AJ, Winkel EG, Goené RJ, Abbas $\mathrm{F}$, de Graff J. Occurrence of Bacteroides gingivalis, Bacteroides intermedius and Actinobacillus actinomycetemcomitans in severe periodontitis in relation to age and treatment history. J Clin Periodontol. 1990;17:392-9.

28- Tinoco EM, Sivakumar M, Preus HR. The distribution and transmission of Actinobacillus actinomycetemcomitans in families with localized juvenile periodontitis. J Clin Periodontol. $1998 ; 25: 99-105$.

29- Tinoco EM, Stevens R, Haubek D, Lai CH, Balachandran S, Preus $\mathrm{H}$. Relationship of serotype, leukotoxin gene type and lysogeny in Actinobacillus actinomycetemcomitans to periodontal disease status. Eur J Oral Sci. 1997;105:310-7.

30- Tonetti MS, Mombelli A. Early-onset periodontitis. Ann Periodontol. 1999;4:39-53.

31- Vieira EM, Raslan SA, Wahasugui TC, Avila-Campos MJ, Marvulle V, Gaetti-Jardim Júnior E. Occurrence of Aggregatibacter actinomycetemcomitans in Brazilian Indians from Umutina Reservation, Mato Grosso, Brazil. J Appl Oral Sci. 2009;17:440-5. 32- Wahasugui TC, Nakano V, Piazza RM, Avila-Campos MJ. Phenotypic and genotypic features of Aggregatibacter actinomycetemcomitans isolated from patients with periodontal disease. Diagn Microbiol Infect Dis. 2013;75:366-72.

33- Wilson $\mathrm{KH}$, Blitchington RB, Greene RC. Amplification of bacterial $16 \mathrm{~S}$ ribosomal DNA with polymerase chain reaction. J Clin Microbiol. 1990;28:1942-6.

34- Zambon JJ, Haraszthy VI. The laboratory diagnosis of periodontal infections. Periodontol 2000. 1995;7:69-82.

35- Zambon JJ, Haraszthy VI, Hariharan G, Lally ET, Demuth DR. The microbiology of early-onset periodontitis: association of highly toxic Actinobacillus actinomycetemcomitans strains with localized juvenile periodontitis. J Periodontol. 1996;67:282-90. 